\title{
$\bullet$ IJCRR \\ Effect of Oral Pregabalin as a Premedicant on Haemodynamic Response to Laryngoscopy and Intubation
}

Section: Healthcare ISI Impact Factor (2019-20): 1.628 IC Value (2019): 90.81 $\operatorname{SJIF}(2020)=7.893$

(c) (i) (8)

Copyright@IJCRR

\author{
Pravinkumaar $\mathbf{R}^{1}$, Aswini L ${ }^{2}$, Uma $\mathbf{R}^{3}$, Shirishkumar Chavan ${ }^{4}$
}

'Assistant Professor of Anaesthesiology, Stanley Medical College, Chennai, India; ${ }^{2}$ Assistant Professor of Anaesthesiology, Esic Medical College and Pgimsr, KK Nagar, Chennai-78, India; ${ }^{3}$ Professor of Anaesthesiology, Acs Medical College, Chennai, India; ${ }^{4}$ Professor and Hod of Anaes-

thesiology, Esic Medical College and Pgimsr, KK Nagar, Chennai-78, India.

\section{ABSTRACT}

Introduction: Laryngoscopy and tracheal intubation are considered the most noxious stimuli, leading to adverse haemodynamic pressor response, especially in cardiovascular compromised patients, necessitating the need to attenuate the pressor responses.

Aim: To study the effects of pregabalin in attenuating the variations in heart rate and blood pressure and relieving anxiety and providing sedation.

Methods: Sixty adult patients between 18-60yrs of both gender of ASA status I and II scheduled for elective surgeries under General anaesthesia satisfying the inclusion criteria were selected and randomly allocated into 2 groups- Group A (Pregabalin 300mg orally) and Group B (Placebo) by closed envelope method. Parameters like SBP, DBP, HR, MAP, SPO2 were noted down. 60 minutes after giving the drug, the Sedation score and Anxiety score were noted down.

Results: After premedication (90 minutes later) with oral Pregabalin 300mg, sedation score, anxiety score, heart rate, systolic blood pressure, diastolic blood pressure, MAP was significantly reduced Pregabalin group than in the placebo group at intubation. Hence pregabalin proved to be effective in blunting the hemodynamic stress response to laryngoscopy and intubation compared to the control group. There was no incidence of bradycardia or hypotension intraoperatively in any group. There was postoperative sedation in the pregabalin group, but it did not interfere with the patient's recovery. The patients in the pregabalin group were less anxious, quiet and comfortable before and after the surgery.

Conclusion: Oral administration of pregabalin 300mg effectively suppressed the cardiovascular response to laryngoscopy and intubation. Pregabalin provided better anxiolysis and sedation without any change in the respiratory pattern compared to the placebo tablet.

Key Words: Pregabalin, Attenuation, Laryngoscopy, Anxiolysis, Premedication

\section{INTRODUCTION}

In spite of vast advances in the art of anaesthetizing a patient, General anaesthesia is still the gold standard when the need to secure the airway arises. So every Anesthesiologist must gain proficiency in administering general anesthesia to a patient in the safest possible manner. Endotracheal intubation consists of inserting an endotracheal tube inside the trachea to maintain airway patency and protection and provide positive pressure ventilation. This is done by direct laryngoscopy but alternative techniques like fibreoptic intubation or retrograde intubation are employed in particular situations. ${ }^{1}$
Laryngoscopy and intubation are considered to be the most noxious stimuli which can lead to adverse haemodynamic pressor response following intubation. ${ }^{1}$ This is usually tolerated by healthy individuals but in susceptible patients, even these haemodynamic fluctuations can have deleterious effects. Left ventricular compromise, myocardial ischemia and cerebral hemorrhage can be precipitated by a sudden increase in blood pressure and heart rate in such patients. Hence adequate preoperative sedation, anxiolysis and analgesia help to ensure cardiovascular stability during induction, laryngoscopy and intubation. ${ }^{2}$ Anxiety still remains a major problem for most patients before any surgery.

Corresponding Author:

Uma R, 265, Dr. A. Lakshmanaswamy Road, KK Nagar, Tamilnadu, Chennai, India.

Phone: 9840822288; Email: rsuma@yahoo.com

ISSN: 2231-2196 (Print)

Received: 23.01 .202
ISSN: 0975-5241 (Online)

Revised: 02.03 .2021
Accepted: 08.04 .2021

Published: 30.08 .2021 
Many drugs like opioids, benzodiazepines, volatile agents, lignocaine spray, beta-blockers, calcium channel blockers have been tried to attenuate these adverse haemodynamic pressor responses due to airway instrumentation as well as to decrease anxiety. ${ }^{2}$ Most common adverse effect of opioids are respiratory depression, PONV and delayed bowel function recovery. The common adverse effects of benzodiazepines are the variability in patient response and respiratory complications. The adverse profile of these drugs creates the need for an alternative drug with sedative, anxiolytic property and efficacy in reducing pressor responses with minimal adverse effects 2,3

Recently, an increasing emphasis has been made on the use of non-opioid drugs as a part of the multimodal regimen for decreasing anxiety and obtunding the intubation response. Many recent studies show that Gamma-aminobutyric acid (GABA) mimetic drugs like gabapentin and pregabalin decrease the stress response due to laryngoscopy and intubation.

Pregabalin is a drug with analgesic, anticonvulsant and anti anxiety ${ }^{2}$ effects mainly used for the management of neuropathic pain, neuralgia occurring post herpes infection and as an adjuvant for the treatment of partial-onset seizures. Its effectiveness in providing postoperative pain relief and reducing the dose of parenteral analgesics are well documented in several studies. ${ }^{4,5,6}$ Only minimal evidence is available in our literature related to the cardiovascular effects of pregabalin in patients undergoing surgery. ${ }^{7,8}$ Hence in this study we decided to find out the efficacy of pregabalin in attenuating the pressor response to tracheal intubation.

\section{AIM}

To study the effects of pregabalin in attenuating the variations in heart rate and blood pressure and also in relieving anxiety and providing sedation.

\section{MATERIALS AND METHODS}

A Prospective, double blinded, randomized, placebo-controlled trial was undertaken in ESIC Medical College \& PGIMSR, KK.Nagar, Chennai-78, in the department of Anaesthesiology for a period of one year from April 2018 to March 2019 after obtaining ethical committee clearance as well as informed consent from all the patients (EC approval No.06/2018).

Sixty adults patients between 20-60 years of either sex of ASA grade I or II scheduled for elective surgeries under general anaesthesia were included in this study after approval of the institutional ethical committee.

\section{Inclusion Criteria}

- ASA grade I and II

- Age 20-60 years of either sex.

- Mallampatti class I and II

- Patients with $\mathrm{BP}<130 / 80$

- Patients with the informed written consent

- $\quad$ BMI $<30 \mathrm{~kg} / \mathrm{m}^{2}$

\section{Exclusion Criteria}

- Patient refusal

- Emergency surgeries

- Systolic BP $<90$, Bradycardia $-\mathrm{HR}<60$

- Anticipated difficult intubation

- Intubation time $>20$ secs

- Pregnancy

- Patients with known cardiovascular diseases like IHD and Hypertension, Renal or liver disease

- Patients on anti-HTN drugs, Rate modifying drugs like beta-blockers, calcium channel blockers

- Duration of surgery $>4 \mathrm{hrs}$

- H/o allergy to pregabalin

Sixty adult patients between 20-60yrs of both gender of ASA status I and II scheduled for elective surgeries under General anaesthesia satisfying the inclusion criteria were selected and informed written consent was obtained from the patients after explaining about the study in the local language of the patient. Height and Weight were recorded.

All the patients on the previous night received T.Alprazolam $0.25 \mathrm{mg}$ orally and T.Ranitidine $150 \mathrm{mg}$, T.metoclopramide $10 \mathrm{mg} 2$ hours before surgery orally.

Patients were randomly allocated into 2 groups- Group A and Group B by the closed envelope method.

1) Group A will receive Pregabalin 300mg orally 90 mins before surgery.

2) Group B will receive a placebo Cap. B-complex orally 90 mins before surgery.

Drugs were given by the principal investigator and the anaesthesia provider was blinded about the drug given to the patient.

Baseline preop parameters like Systolic blood pressure (SBP, Diastolic blood pressure (DBP), Heart rate (HP), Mean arterial pressure (MAP), Peripheral capillary oxygen saturation(SPO), were noted down. 60 minutes after giving the drug, the Sedation score and Anxiety score were noted down. Vital parameters like HR, BP, MAP, Spo2, EtCO2were recorded at premedication, induction, intubation, $1 \mathrm{~min}$, $3 \mathrm{~min}, 5 \mathrm{~min}, 10 \mathrm{~min}$ after intubation and every $30 \mathrm{mins}$ till the end of surgery.

The patient was monitored for any intraoperative complications like Bradycardia, Hypotension and treated accordingly. During the preoperative and postoperative period patient was 
monitored for complications like nausea, vomiting and giddiness.

Descriptive statistics were done for all data and were reported in terms of mean values and percentages. Continuous variables were analysed with the unpaired t-test. Categorical variables were analysed with the Chi-Square Test and Fisher Exact Test. Statistical significance was taken as $\mathrm{p}<0.05$.

\section{RESULTS}

Table 1: Descriptive statistics for two groups

\begin{tabular}{|c|c|c|c|c|}
\hline \multicolumn{2}{|c|}{$\begin{array}{l}\text { Baseline character- } \\
\text { istics }\end{array}$} & $\begin{array}{c}\text { Group P } \\
\text { (N=30) } \\
\text { Pregabalin } \\
\text { Group }\end{array}$ & $\begin{array}{c}\text { Group C } \\
(\mathrm{N}=30) \text { Con- } \\
\text { trol-Placebo } \\
\text { Group }\end{array}$ & $\begin{array}{c}\text { P- } \\
\text { Value }\end{array}$ \\
\hline \multicolumn{2}{|l|}{ Age (Years) } & $29.30 \pm 8.35$ & $32.93 \pm 10.94$ & 0.154 \\
\hline \multirow[t]{2}{*}{ Gender } & Male & 16 & 12 & \multirow[t]{2}{*}{0.309} \\
\hline & Female & 14 & 18 & \\
\hline Weight (Kgs) & & $59.47 \pm 9.62$ & $57.40 \pm 6.37$ & 0.331 \\
\hline Height (mts) & & $1.60 \pm 0.07$ & $1.57 \pm 0.05$ & 0.053 \\
\hline BMI $\left(\mathrm{Kg} / \mathrm{m}^{2}\right)$ & & $23.04 \pm 2.57$ & $23.18 \pm 2.23$ & 0.83 \\
\hline \multirow[t]{2}{*}{ ASA } & I & 29 & 26 & \multirow[t]{2}{*}{0.168} \\
\hline & II & 1 & 4 & \\
\hline
\end{tabular}

Values are given as mean \pm standard deviation, or number of patients(\%).

Data collected from 60 selected subjects were internally compared, tabulated, analysed and interpreted by using descriptive and inferential statistics based on the formulated objectives of the study. There were no statistically significant differences in the demographics of the two groups in this study ( $>0.05)$ Table 1.

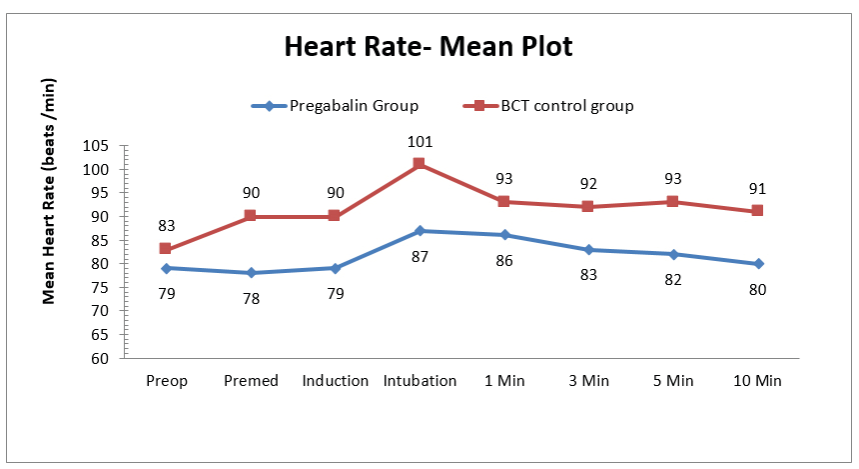

Figure 1: Heart rate comparison between two groups.

While analysing heart rate distribution among 60 patients included in this study, it was observed that the mean pre-operative HR in the Pregabalin group was $79.20 \pm 8.99$ beats/ min and in the BCT group the mean pre-operative HR was $83 \pm 12.88$ beats $/ \mathrm{min}(\mathrm{p}=0.191)$ (Figure 1$)$.
During premedication, the mean HR in the Pregabalin group was $78.3 \pm 14.34$ beats $/ \mathrm{min}$ and in the BCT group the mean pre-operative HR was $89.7 \pm 16.71$ beats $/ \mathrm{min}(\mathrm{p}=0.006)$. During induction, the mean HR in the Pregabalin group was $78.47 \pm 12.07$ beats/min and in the BCT group the mean pre-operative HR was $89.57 \pm 17$ beats $/ \mathrm{min}(\mathrm{p}=0.005)$. During intubation, the mean HR in the Pregabalin group was $87.43 \pm 14.64$ beats $/ \mathrm{min}$ and in the BCT group the mean preoperative HR was $101 \pm 13.7$ beats/min $(p=0.01)$ showing a significant increase of $8 \mathrm{bpm}$ in the Pregabalin group and $18 \mathrm{bpm}$ in BCT group from baseline. After intubation, the mean HR in the Pregabalin group was $85.7 \pm 13.72 \mathrm{bpm}$ at 1 $\mathrm{min}, 82.73 \pm 12.65 \mathrm{bpm}$ at $3 \mathrm{mins}, 81.7 \pm 14.77 \mathrm{bpm}$ at $5 \mathrm{mins}$ and $80.13 \pm 15.59 \mathrm{bpm}$ at $10 \mathrm{mins}$ and in the BCT group, the mean HR was $93.1 \pm 17.14 \mathrm{bpm}$ at $1 \mathrm{~min}, 91.57 \pm 17.76 \mathrm{bpm}$ at 3 mins, $92.63 \pm 15.74 \mathrm{bpm}$ at $5 \mathrm{mins}$ and $90.63 \pm 12.48 \mathrm{bpm}$ at 10 mins. The data reveals the existence of a statistically nonsignificant association in heart rate distribution between the Pregabalin group and BCT group during pre-operative and 1 minute after intubation $(p>0.05)$. But the data reveals the existence of a statistically significant association in difference in heart rate distribution between the Pregabalin group and $\mathrm{BCT}$ group during premedication, induction, intubation, 3 mins, 5 mins and 10 mins after intubation $(p<0.05)$.

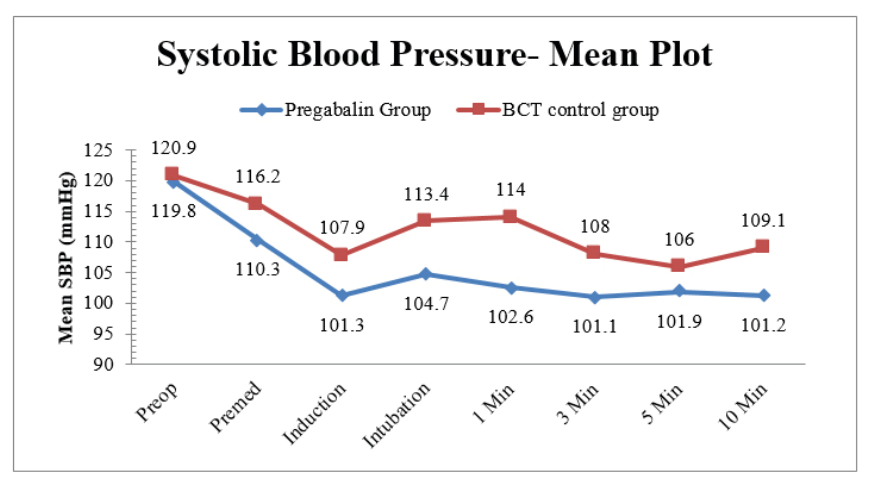

Figure 2: Systolic Blood Pressure comparison between two groups.

While analysing SBP distribution among 60 patients undergoing elective surgeries under general anaesthesia, it was observed that the mean pre-operative SBP in the Pregabalin group was $119.8 \pm 9.6 \mathrm{mmHg}$ and in the BCT group the mean pre-operative SBP was $120.9 \pm 12.7 \mathrm{mmHg}(\mathrm{p}=0.706$, unpaired t-test) ( Figure 2).

During premedication, the mean SBP in the Pregabalin group was $110.3 \pm 14.6 \mathrm{mmHg}$ and in the BCT group the mean pre-operative SBP was $116.2 \pm 13 \mathrm{mmHg}$ ( $\mathrm{p}=0.102$, unpaired t-test). During induction, the mean SBP in the Pregabalin group was $101.3 \pm 8 \mathrm{mmHg}$ and in the $\mathrm{BCT}$ group the mean pre-operative SBP was $107.9 \pm 15.1 \mathrm{mmHg}$ ( $\mathrm{p}=$ 0.04, unpaired t-test). During intubation, the mean SBP in the Pregabalin group was $104.7 \pm 13.9 \mathrm{mmHg}$ and in the BCT 
group the mean pre-operative SBP was $113.4 \pm 16.7 \mathrm{mmHg}$ $(p=0.03$, unpaired t-test) showing a significant decrease of $16 \mathrm{mmHg}$ in the Pregabalin group and $8 \mathrm{mmHg}$ in the BCT group from baseline preop value and significant increase of 3 $\mathrm{mmHg}$ in Pregabalin group and $6 \mathrm{mmHg}$ in BCT group from induction value. After intubation the mean SBP in Pregabalin group was $102.6 \pm 11.1 \mathrm{mmHg}$ at $1 \mathrm{~min}, 101.1 \pm 10.6 \mathrm{mmHg}$ at $3 \mathrm{mins}, 101.9 \pm 8.8 \mathrm{mmHg}$ at $5 \mathrm{mins}$ and $101.2 \pm 9.9 \mathrm{mmHg}$ at 10 mins and in BCT group the mean SBP was $114 \pm 18.8$ $\mathrm{mmHg}$ at $1 \mathrm{~min}, 108 \pm 15.9 \mathrm{mmHg}$ at $3 \mathrm{mins}, 106 \pm 11.8$ $\mathrm{mmHg}$ at $5 \mathrm{mins}$ and $109.1 \pm 13.9 \mathrm{mmHg}$ at $10 \mathrm{mins}$. The data reveals the existence of a statistically non-significant difference in SBP distribution between the Pregabalin group and $\mathrm{BCT}$ group during pre-operative, premedication, 3 mins and 5 mins after intubation $(\mathrm{p}>0.05)$. But the data reveals the existence of a statistically significant difference in SBP distribution between the Pregabalin group and BCT group during induction, intubation and 10 mins after intubation ( $\mathrm{p}$ $<0.05)$.

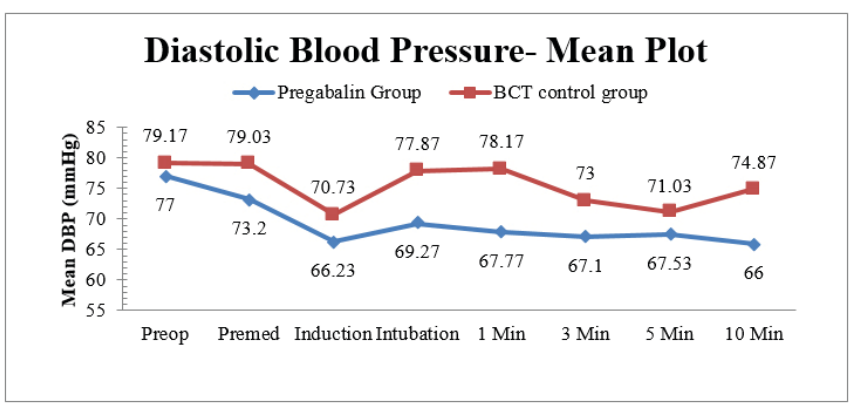

Figure 3: Diastolic Blood Pressure comparison between two groups.

While analyzing DBP distribution among 60 patients undergoing elective surgeries under general anaesthesia, it was observed that the mean pre-operative DBP in the Pregabalin group was $77 \pm 7.46 \mathrm{mmHg}$ and in the $\mathrm{BCT}$ group the mean pre-operative DBP was $79.17 \pm 7.58 \mathrm{mmHg}(\mathrm{p}=0.269$, unpaired t-test) ( Figure 3).

During premedication, the mean DBP in the Pregabalin group was $73.20 \pm 10.2 \mathrm{mmHg}$ and in the BCT group, the mean pre-operative DBP was $79.03 \pm 8.97 \mathrm{mmHg}(\mathrm{p}=0.022$, unpaired t-test). During induction, the mean DBP in the Pregabalin group was $66.23 \pm 7.12 \mathrm{mmHg}$ and in the BCT group, the mean pre-operative DBP was $70.73 \pm 10.37 \mathrm{mmHg}$ ( $\mathrm{p}=$ 0.055 , unpaired t-test). During intubation, the mean DBP in the Pregabalin group was $69.27 \pm 10.52 \mathrm{mmHg}$ and in the BCT group, the mean pre-operative DBP was $77.87 \pm 14.35$ $\mathrm{mmHg}(\mathrm{p}=0.01$, unpaired $\mathrm{t}$-test $)$ showing a significant decrease of $8 \mathrm{mmHg}$ in the Pregabalin group and $1.5 \mathrm{mmHg}$ in the BCT group from baseline preop value and significant increase of $3 \mathrm{mmHg}$ in Pregabalin group and $7 \mathrm{mmHg}$ in $\mathrm{BCT}$ group from induction value. After intubation the mean
DBP in Pregabalin group was $67.77 \pm 8.19 \mathrm{mmHg}$ at $1 \mathrm{~min}$, $67.10 \pm 6.29 \mathrm{mmHg}$ at $3 \mathrm{mins}, 67.53 \pm 8.27 \mathrm{mmHg}$ at $5 \mathrm{mins}$ and $66 \pm 10.12 \mathrm{mmHg}$ at $10 \mathrm{mins}$ and in BCT group the mean DBP was $78.17 \pm 14.29 \mathrm{mmHg}$ at $1 \mathrm{~min}, 73 \pm 11.13 \mathrm{mmHg}$ at 3 mins, $71.03 \pm 9.5 \mathrm{mmHg}$ at $5 \mathrm{mins}$ and $74.87 \pm 11.98 \mathrm{mmHg}$ at 10 mins. The data reveals the existence of a statistically nonsignificant difference in DBP distribution between the Pregabalin group and BCT group during pre-operative, induction and 5 mins after intubation $(\mathrm{p}>0.05)$. But the data reveals the existence of a statistically significant difference in DBP distribution between the Pregabalin group and BCT group during premedication, intubation, 1 minute, 3 mins and 10 mins after intubation $(\mathrm{p}<0.05)$.

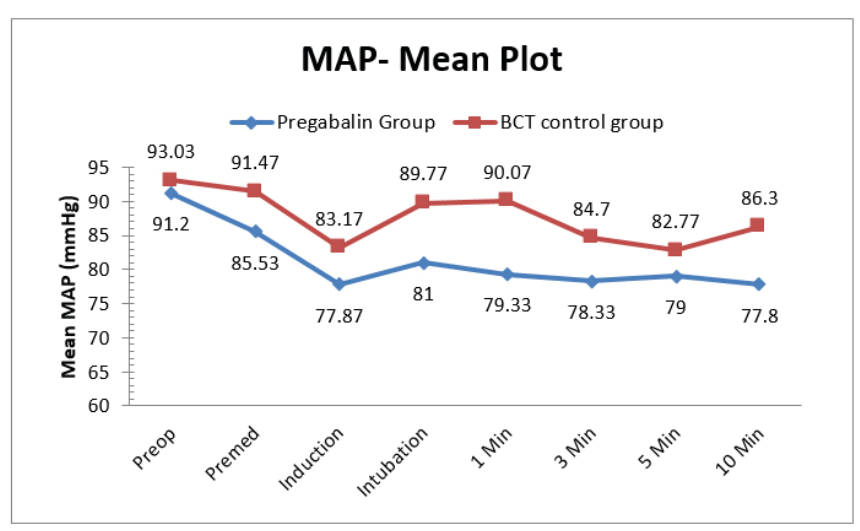

Figure 4: MAP comparison between two groups.

While analysing MAP distribution among 60 patients included in this study, it was observed that the mean pre-operative MAP in the Pregabalin group was $91.20 \pm 7.15 \mathrm{mmHg}$ and in the $\mathrm{BCT}$ group, the mean pre-operative MAP was $93.03 \pm 8.76$ $\mathrm{mmHg}(\mathrm{p}=0.378$, unpaired t-test) ( Figure 4).

During premedication, the mean MAP in the Pregabalin group was $85.53 \pm 10.95 \mathrm{mmHg}$ and in the BCT group, the mean pre-operative MAP was $91.47 \pm 9.62 \mathrm{mmHg}(\mathrm{p}=0.03$, unpaired t-test). During induction, the mean MAP in the Pregabalin group was $77.87 \pm 6.63 \mathrm{mmHg}$ and in the BCT group, the mean pre-operative MAP was $83.17 \pm 11.15 \mathrm{mmHg}$ ( $\mathrm{p}=$ 0.029, unpaired t-test). During intubation, the mean MAP in the Pregabalin group was $81 \pm 11.18 \mathrm{mmHg}$ and in the BCT group, the mean pre-operative MAP was $89.77 \pm 14.42$ $\mathrm{mmHg}(\mathrm{p}=0.011$, unpaired t-test) showing a significant decrease of $10 \mathrm{mmHg}$ in the Pregabalin group and $3 \mathrm{mmHg}$ in BCT group from baseline preop value and significant increase of $3 \mathrm{mmHg}$ in Pregabalin group and $6 \mathrm{mmHg}$ in $\mathrm{BCT}$ group from induction value. After intubation the mean MAP in Pregabalin group was $79.33 \pm 8.84 \mathrm{mmHg}$ at $1 \mathrm{~min}$, $78.33 \pm 7.12 \mathrm{mmHg}$ at $3 \mathrm{mins}, 79 \pm 7.73 \mathrm{mmHg}$ at $5 \mathrm{mins}$ and $77.80 \pm 9.49 \mathrm{mmHg}$ at 10 mins and in BCT group the mean MAP was $90.07 \pm 15.41 \mathrm{mmHg}$ at $1 \mathrm{~min}, 84.7 \pm 12.28 \mathrm{mmHg}$ at 3 mins, $82.77 \pm 9.57 \mathrm{mmHg}$ at $5 \mathrm{mins}$ and $86.30 \pm 12.14$ $\mathrm{mmHg}$ at 10 mins. The data reveals the existence of a statisti- 
cally non-significant difference in MAP distribution between the Pregabalin group and BCT group during pre-operative and 5 mins after intubation $(p>0.05)$. But the data reveals the existence of a statistically significant difference in MAP distribution between the Pregabalin group and BCT group during premedication, induction, intubation, 1 minute, 3 mins and 10 mins after intubation $(\mathrm{p}<0.05)$ ( Figure 5).

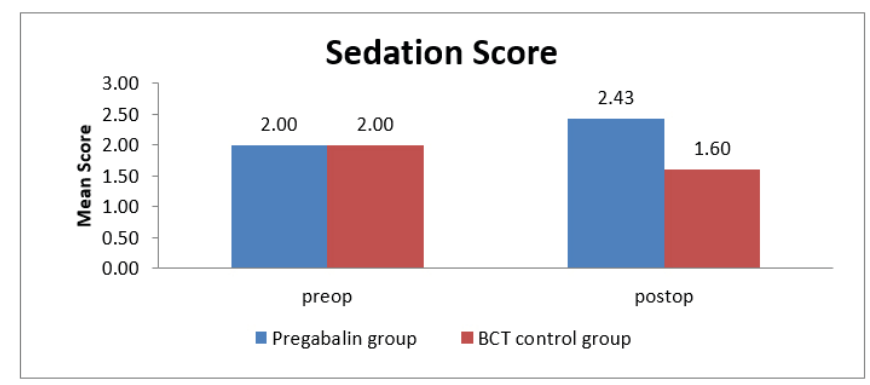

Figure 5: Sedation score comparison between two groups.

The mean preop and postop sedation score in the Pregabalin group was $2 \pm 0.00$ and $2.43 \pm 0.50$, respectively (p-value $<0.001$, paired t-test). The mean preop and postop sedation score in the BCT group was $2 \pm 0.00$ and $1.60 \pm 0.50$, respectively (p-value $<0.001$, paired t-test). Hence when comparing the mean preop and postop sedation scores within the same group, the sedation score was found to be statistically significant in both groups $(\mathrm{p}<0.05)$.

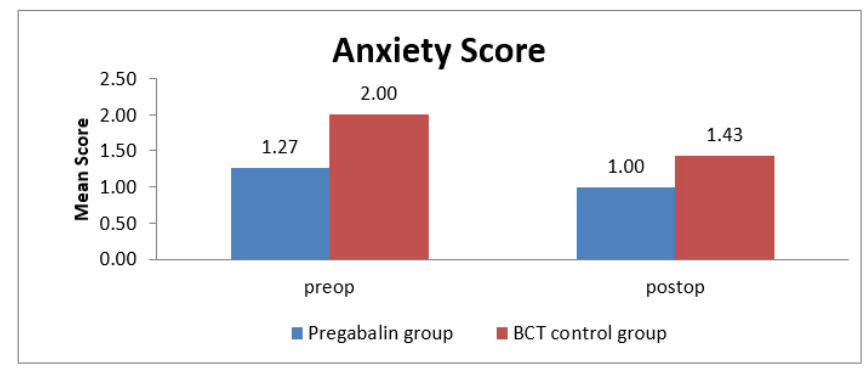

Figure 6: Anxiety Score comparison between two groups.

The mean preop anxiety score in the Pregabalin group was $1.27 \pm 0$ and in the BCT group, the scores were $2 \pm 0.26$ (pvalue $=<0.001$, unpaired t-test). The mean postop anxiety score in pregabalin group were $1 \pm 0$ and $1.43 \pm 0.50$ in BCT group ( $\mathrm{p}$-value $=<0.001$, unpaired t-test). Hence when comparing the mean anxiety score between the two groups, the preop anxiety score and the postop anxiety score were found to be statistically significant $(\mathrm{p}<0.05)$ ( Figure 6).

\section{DISCUSSION}

Gabapentin and pregabalin are structural analogues of gamma-aminobutyric acid, initially developed for the treatment of epilepsy and also for the effective management of neuropathic pain. They are also used in the perioperative period to provide pain relief. ${ }^{4,5,6}$ Recently; these drugs are being used in the preoperative setting to blunt the cardiovascular stress response occurring during laryngoscopy and tracheal intubation but with different doses and conflicting results., ${ }^{9,10,11}$

In our study during intubation, the mean HR in the Pregabalin group was 87 beats/min and in the BCT group, the mean pre-operative HR was 101 beats/minute. We found a significant increase in heart rate of $8 \mathrm{bpm}$ in pregabalin groups which received $150 \mathrm{mg}$ dose of pregabalin compared to the control group. This is consistent with the study done by Rastogi et al. and co-workers, where the study was carried out with two different doses of pregabalin of $75 \mathrm{mg}$ and $150 \mathrm{mg} .{ }^{10}$

Doddaiah et al. ${ }^{12}$, who did a comparative study of oral pregabalin $150 \mathrm{mg}$ and oral gabapentin $800 \mathrm{mg}$ in the attenuation of hemodynamic response to laryngoscopy and intubation, found that both the groups decreased the HR, BP, MAP when compared to the control group during intubation, $1 \mathrm{~min}$ and 5 mins. But there was no statistical significance between the two groups in reducing the heart rate at intubation.

In our study during intubation, the mean SBP in the Pregabalin group was $104.7 \mathrm{mmHg}$ and in the BCT group, the mean pre-operative SBP was $113.4 \mathrm{mmHg}$. This is consistent with a study done by Sundar et al. ${ }^{13}$ and co-workers who observed the effectiveness of pre-emptive pregabalin on the attenuation of stress response to endotracheal intubation and opioidsparing effect in a patient undergoing off-pump coronary artery bypass grafting.

In our study during intubation, the mean DBP in the Pregabalin group was $69.27 \mathrm{mmHg}$ and in the BCT group, the mean pre-operative DBP was $77.87 \mathrm{mmHg}$. This is consistent with a study done by Sundar et al. ${ }^{13}$ and co-workers observed a decrease in diastolic blood pressure of $22 \mathrm{mmHg}$ in pregabalin groups.

The sedation score among 60 patients undergoing elective surgeries under general anaesthesia was analyzed. The preoperative sedation score for all 30 patients in both the Pregabalin group and BCT group were 2 as per the Ramsay sedation scale. Postop sedation scores for $57 \%$ of the patients in the Pregabalin group and $60 \%$ of patients in BCT groups were score 2 . The postop sedated score in the remaining $43 \%$ in pregabalin groups was score 3 . These results are consistent with the study done by Waikar et al. ${ }^{14}$ who compared pregabalin, gabapentin and clonidine and found both pregabalin and gabapentin provided sedation.

\section{CONCLUSION}

Pregabalin 300mg proved to be an effective drug in blunting the hemodynamic stress response to laryngoscopy and intubation and also in providing sedation and in relieving 
anxiety. The sedation score, anxiety score, heart rate, systolic blood pressure, diastolic blood. pressure, MAP was significantly reduced in the Pregabalin group than in the placebo group at intubation. The ideal drug which can blunt the stress response provides sedation. and anxiolysis with the least adverse profile was not found.

\section{Limitations of the study}

1. Though we excluded laryngoscopy time $>20$ secs from the study, we did not measure the laryngoscopy time in our study.

2. We did not measure the stress mediators like catecholamine levels in plasma though its correlation with intubation is controversial in the literature.

3. In inclusion criteria, cases could have been narrowed down to specific surgical procedures rather than including all GA cases.

\section{ACKNOWLEDGEMENT}

Authors acknowledge the immense help received from the scholars whose articles are cited and included in references to this manuscript

\section{Conflict of interest: Nil}

Financial support: No

\section{REFERENCES}

1. King BD, Harris LC, Greifenstein FE, Elder JD, Dripps RD. Reflex circulatory responses to direct laryngoscopy and tracheal intubation performed during general anaesthesia. Anesthesiology. 1951 Sep 1;12(5):556-66.

2. Field MJ, Oles RJ, Singh L. Pregabalin may represent a novel class of anxiolytic agents with a broad spectrum of activity. Br J Pharmacol. 2001 Jan;132(1):1-4.

3. Kovac AL. Controlling the hemodynamic response to laryngoscopy and endotracheal intubation. J Clin Anesth. 1996 Feb 1;8(1):63-79.
4. Ghai A, Gupta M, Hooda S, Singla D, Wadhera R. A randomized controlled trial to compare pregabalin with gabapentin for postoperative pain in abdominal hysterectomy. Saudi J Anaesth.. $2011 \mathrm{Jul} ; 5(3): 252$.

5. Kohli M, Murali T, Gupta R, Khan P, Bogra J. Optimization of the subarachnoid block by oral pregabalin for hysterectomy. J Anaesthesiol Clin Pharmacol. 2011 Jan;27(1):101.

6. Durkin B, Page C, Glass P. Pregabalin for the treatment of postsurgical pain. Expert Opin Pharmacother. 2010 Nov 1;11(16):2751-8.

7. Ali A, Elnakera A, Samir A. Effect of Two Different Doses of Gabapentin on the Intraocular Pressure and Hemodynamic Stress Responses to Laryngoscopy and Tracheal Intubation. Int Sch Res Notices. 2013:1-5.

8. Pristautz H, Biffl H, Pinl F, Leitner W, Parsché P, Borkenstein J. The influence of a beta-adrenolytic premedication on cardiovascular parameters and plasma free fatty acids during oesophagusgastro-duodenoscopy (author's transl). Wiener medizinische Wochenschrift (1946). 1979 Dec 1;199(24):707-12.

9. Eren G, Kozanhan B, Hergunsel O, Bilgin U, Demir G, Cukurova $Z$. Pregabalin blunts cardiovascular responses to laryngoscopy and tracheal intubation. J Anesthesiol Reanim. 2009;7:82-7.

10. Rastogi B, Gupta K, Gupta PK, Agarwal S, Jain M, Chauhan H. Oral pregabalin premedication for attenuation of the haemodynamic pressor response of airway instrumentation during general anaesthesia: A dose-response study. Indian J Anaesth. 2012 Jan;56(1):49.

11. Gupta K, Bansal P, Gupta PK, Singh YP. Pregabalin premedication-A new treatment option for hemodynamic stability during general anaesthesia: A prospective study. Anesth Essays Res. 2011 Jan;5(1):57.

12. Doddaiah DB, Singh NR, Fatima N, Singh SS, Singh HK, Singh KS. A comparative study of oral pregabalin and oral gabapentin in the attenuation of hemodynamic response to laryngoscopy and intubation. J Med Soc. 2017 Jan 1;31(1):14.

13. Sundar AS, Kodali R, Sulaiman S, Ravullapalli H, Karthikeyan $\mathrm{R}$, Vakamudi M. The effects of preemptive pregabalin on attenuation of stress response to endotracheal intubation and opioidsparing effect in patients undergoing off-pump coronary artery bypass grafting. Ann Card Anaesth. 2012 Jan 1;15(1):18.

14. Waikar C, Singh J, Gupta D, Agrawal A. Comparative study of oral gabapentin, pregabalin, and clonidine as premedication for anxiolysis, sedation, and attenuation of pressor response to endotracheal intubation. Anesth Essays Res. 2017 Jul;11(3):558. 